\title{
Assessment of swimming behavior of Pacific oyster D-larvae (Crassostrea gigas) following exposure to model pollutants
}

\author{
Perrine Gamain ${ }^{1}$, Alicia Roméro-Ramirez ${ }^{1}$, Patrice Gonzalez ${ }^{1}$, Nicolas Mazella², Pierre Yves \\ Gourves $^{1}$, Clémence Campan, Bénédicte Morin ${ }^{1}$, Jérôme Cachot ${ }^{1}$ \\ ${ }^{1}$ Univ. Bordeaux, EPOC, UMR 5805, F-33400 Talence, France \\ ${ }^{2}$ IRSTEA, URBEX (Water Research Unit), 50 avenue de Verdun, Gazinet, 33612 Cestas Cedex, \\ France \\ Corresponding author: jerome.cachot@u-bordeaux.fr \\ Tel: +33 (0)5 40003830 / Fax: +33 (0)5 40008719
}

This study describes an image analysis method that has been used to analyze early life stages behavior of native oysters (Crassostrea gigas) from the Arcachon Bay (SW, France). In a second time, this study evaluated the impact of $\mathrm{Cu}$ and S-metolachlor pollutants on D-larvae behavior and possible relationship between developmental malformations and abnormal swimming behavior. Analyses in wild and cultivated oyster D-larvae were investigated during two breeding-seasons (2014 and 2015) at different sampling sites and dates. In control condition, the average speed of larvae was $144 \mu \mathrm{m} \cdot \mathrm{s}^{-1}$ and the maximum speed was $297 \mu \mathrm{m} \cdot \mathrm{s}^{-1}$ while the trajectory is mainly rectilinear. In the presence of environmental concentration of copper or S-metolachlor, no significant difference in maximum or average larval speed was observed compared to the control condition but the percentage of circular trajectory increased significantly while the rectilinear swimming larvae significantly declined. The current study demonstrates that rectilinear trajectories are positively correlated to normal larvae while larvae with shell anomalies are positively correlated to circular trajectories. This aberrant behavior could impacts the survival and spread of larvae and consequently the recruitment and colonization of new habitats.

Key words: early life stage; Image analysis; speed; trajectory; malformations; copper; Smetolachlor, swimming behavior.

\section{Introduction}


Behavioral analysis is increasingly used to study the effects of chemicals and drugs on humans and other mammals $(X X X)$. In recent years, many biological early warning systems have been developed that evaluate the behavioral responses of aquatic organisms to water quality (Melvin and Wilson, 2013; Garaventa et al., 2010; Van der Schalie et al., 2001). In contrast, effects of contaminants on aquatic invertebrate behavior are less frequently studied in comparison to developmental or reproductive toxicology (Melvin and Wilson, 2013; Scott and Sloman, 2004). However, behavioral indicators of toxicity appear ideal for assessing the effects of pollutants on aquatic organisms since they link physiological function with ecological processes (Scott and Sloman, 2004). In aquatic toxicology, the link between behavioral science and impacts of toxic substances only took importance over the last decade (review in Faimali et al., 2017). The behavior can be the result of adaptations to environmental variables. Therefore, a selective response is permanently adapted by direct interaction with the physiological aspects of the chemical and physical social environment. Thus, the study of behavioral parameters now represents valuable tools to identify and assess the effects of exposure to environmental stressors. Until a few years ago, the development of tools facilitating image acquisition and behavioral endpoints, could explain this phenomenon (Melvin and Wilson, 2013). In recent years, much progress has been made in the technological tools available for quantifying behavior (Lv et al., 2013). Thus, the study of behavioral parameters now represents valuable tools to identify and assess the effects of exposure to environmental stressors. Many studies have focused on the behavioral study of fish larvae or adults (Caldwell et al., Handy et al., 1999; Kazlauskiene et al., 2010; Le Bihanic et al., 2015; Sommers et al., 2016; McCallum et al, 2017; Martin et al., 2017). Very few studies have focused on mollusks and more particularly on bivalves (review in Faimali et al., 2017). However, bivalve mollusks such as mussels, clams and oysters contribute significantly to world aquaculture production and the same species have been used as sentinel for pollution monitoring of coastal marine waters The Pacific oyster Crassostrea gigas (Thunberg) is ranked number one in terms of world aquaculture production with 555913 tons estimated in 2013 (FAO, 2015). Despite living attached for most of their life stages, bivalves have a swimming larval stage, which play an important part for the colonization of the environment. In C. gigas embryos incubated at $20^{\circ} \mathrm{C}$, the first movements were observed in trochophore at 6.5 hours post-fertilization (hpf) and most of individual (85\%) can swim at $11.5 \mathrm{hpf}$ (Suquet et al., 2013). Up to now, only a few works has focused on the swimming behavior of early life stage of marine bivalves (Mileikovsky, 1973; Toost et al., 2008) and only a few ones have investigated the abiotic factors as pH, salinity (Suquet et al., 2012; Suquet et al., 2013) and pollutants (Horiguchi et al., 1998) on swimming capacities of bivalves. To our knowledge, none investigated the impact of pollutants on oyster larval swimming capacities. 
To analyze the possible impact of pollutants on oyster larval behavior, two pesticides, copper and metolachlor, frequently occurring in the marine coastal water were tested. Copper $(\mathrm{Cu})$ is among the most hazardous metal for bivalve larvae (His et al., 1999). Although $\mathrm{Cu}$ is an essential micronutrient for living organisms (Festa and Thiele, 2011), it can be toxic above a certain concentration depending on the organism (Flemming and Trevors, 1989). All over the world, $\mathrm{Cu}$ is used both as fungicide in fruit culture and as part of antifouling paint to prevent aquatic organisms from attaching themselves to the hulls of vessels (Turner, 2010). Copper concentrations in the Arcachon Bay have been increasing for several years and current levels exceed $\mu \mathrm{g} . \mathrm{L}^{-1}$ (Gamain et al., 2016). The impact of copper on aquatic organism behavior has already been documented on fish (Sommers et al., 2016). Pesticide contamination in Arcachon Bay is widely dominated by the herbicide S-metolachlor at around $10 \mathrm{ng} . \mathrm{L}^{-}$ ${ }^{1}$ and its metabolites (Auby et al., 2007; Budzinski et al., 2011; Gamain et al., 2016). In fact, Arcachon Bay is end recipient of several rivers draining a watershed of $4138 \mathrm{~km}^{2}$ (Auby et al., 2014), which is mainly dominated by agriculture and urban areas. Metolachlor is used in agriculture to control preemergent and early post-emergent broadleaf and grass weeds, and is regularly detected in surface water and groundwater.

The main objective of this paper is to study the behavior of D-larvae of oysters, Crassostrea gigas in response to copper or S-metolachlor exposure. In order to do that, a method based on image analysis was developed. The open-source program ImageJ (https://imagej.nih.gov/ij/) and the ImageJ Plugin wrMTrck were used. This plugin was initially developed to study the motility of the nematoda Caenorhabditis elegans while swimming in liquids (Nussbaum-krammer et al. 2015) and it presents therefore an interesting similarity with swimming larvae. The method allows analyzing multiple parameters including the total travelled length, the distance and the speed of larvae.

This paper aims to: 1 ) describe an image analysis method that has been used to analyze D-larvae behavior, 2) apply this process to assess the impact of $\mathrm{Cu}$ and S-metolachlor pollutants on D-larvae behavior and 3) investigate possible relationship between developmental malformations and abnormal swimming behavior.

\section{Materials and methods}

\subsection{Method based on imagery}

\subsubsection{Image acquisition}

To analyze the behavior of the native oyster, wild and cultivated oysters were collected during oyster breeding period (July and August 2014 and 2015) from three different sites in the Arcachon Bay: Comprian, Les Jacquets and Banc d'Arguin (Fig. 1). Comprian is located close to the River L'Eyre and 
therefore is under the influence of fresh water inputs in contrast to Les Jacquets or to Arguin. The reference water was collected near the Banc d'Arguin. Adult oysters were brought back to the laboratory in tanks filled with seawater from the sampled site and were kept overnight in this water continuously aerated and maintained at $12^{\circ} \mathrm{C}$.

Mature oysters (male and female) were induced to spawn by thermal stimulation, alternating immersion in $\mathrm{FSW}$ of $15^{\circ} \mathrm{C}$ and $28^{\circ} \mathrm{C}$ for $30 \mathrm{~min}$. Spawning males and females were individually isolated in beakers containing $500 \mathrm{~mL}$ of $0.2 \mu \mathrm{m} \mathrm{FSW}$ at the spawning temperature. They were left undisturbed for $15 \mathrm{~min}$ and were then removed from beakers. Eggs and sperm from two individuals were selected to give a single pairing. Sperms and eggs were sieved separately through a $50 \mu \mathrm{m}$ and $100 \mu \mathrm{m}$ meshes (Sefar Nitex), respectively to eliminate debris and feces. Sperm mobility was checked and the number of eggs was counted under microscope (LEICA DME) at a magnification of 100. Eggs were fertilized with sperm in ratio of 1:10 (egg:sperm) homogenizing with an agitator to prevent polyspermy. Fertilization success was verified under microscope, and embryos were then counted and transferred to 24-well microplate (Greiner Bio-One, Cellstar free of detectable DNase, RNase, human DNA and pyrogens) for embryotoxicity assays. The embryotoxicity assay has been described in details by His et al. (1999) and Quiniou et al. (2005) and normalized (AFNOR 2009). Fertilized eggs (around 300 eggs) were exposed in wells containing $2 \mathrm{ml}$ of toxicant solution. The eggs density was slightly changed compare to the recommended AFNOR document specifying densities between 20000 and 50000 embryos per liter. These microplates were incubated in climatic chamber at $24^{\circ} \mathrm{C}$ for $24 \mathrm{~h}$ in the dark.

After $24 \mathrm{~h}$ incubation, a 2-minute film was recorded by means of a microscope (Nikon Inverted Microscope Eclipse TS 100 / TS100-F, TS100LED MV / MV F-TS100 LED) and an acquisition software (NIS Element D). Recorded films were on a MPEG format and included 100 frames per second.

\subsubsection{Description of the image analysis process}

A freeware (VirtualDub) for video conversion has been used to subsample the film to $4 \mathrm{fps}$ and convert it into AVI format. The AVI format is used within ImageJ. The entire flow of analysis as well as the expected results are schematized on Fig. 2. The films (.avi) are opened as a stack of images (Fig. 2A) and converted into grayscale (Fig.2B). The entire stack of images is then converted into a binary stack of images using the maximum entropy (Kapur et al., 1985) of their histogram to stablish a threshold (Fig. 2C). When running the wrMTrck plugin, proper settings to track oyster larvae were selected (Table $1)$.

As a result, each tracked larvae had a number assigned, each number is used to identify the tracked larvae in the result file. The result file (Fig. $2 \mathrm{E}$ ) include: the track number, the length which is the sum of all movement vectors (pixel), the distance which is the distance between the start and the finish 
134 position (pixel), the number of frames, the first frame, the total time (seconds), the maximum speed 135 (pixel/second), the mean and the standard deviation of the surface of a larva during the tracked period 136 (pixel $\left.{ }^{2}\right)$, the mean and the standard deviation of the perimeter of a larva during the tracked period 137 (pixel), the average speed, the body length per second, the average $X$ position of the larva during the tracked period and the average $Y$ position of the larva during the tracked period. A drawing gathering all tracked larval paths detected throughout the video (Fig. 2D) is also obtained as a result. The gathering drawing allowed to identify three different types of traces of larval path: (1) Rectilinear, defined as the trajectory in which the length and the distance are quite similar (Track 1 Fig. 3), (2) Circular, defined as the trajectory in which the length is a lot bigger than the distance (Track 2 Fig. 3),

143 (3) motionless, in which the length has a low value (Track 3 from Fig. 3). It is important to note that a 144 single larva can be detected multiple times since they can exit and enter the field of view (Track 4 from 145 Fig. 3). Furthermore, two larvae may collide, if it is the case, their larval path may be altered (Track 5 from Fig. 3).

Table 1: Optimized settings for wrMTrck plugin

\begin{tabular}{ll}
\hline Parameters for tracking oyster D-larvae in 'wrMTrck' & Value \\
\hline Minimum size (pixel $^{2}$ ) & 400 \\
Maximum size $\left(\right.$ pixel $^{2}$ ) & 1000 \\
Maximum velocity (pixels/frame) & 100 \\
Maximum area change (\%) & 50 \\
Minimum track length & 20 \\
Threshold for turn & 2 \\
Size of bin for speed histogram (pixel frame) & 0 \\
Show Path Length & Yes \\
Show Labels & Yes \\
Show Positions & Yes \\
Show Paths & Yes \\
Show summary & Yes \\
Smoothing & Yes \\
Raw Data (0:off, 5:bendcalc) & 0 \\
Ben detection (0:off, 3:AR+Histogram) & 0 \\
Frame per second & 4 \\
Background subtraction (0:off) & 0
\end{tabular}




\subsection{Developmental abnormalities}

152

153

154

155

156

157

At the end of the $24 \mathrm{~h}$ incubation, $25 \mu \mathrm{L}$ of $1 \%$ buffered formalin were added in each well and the percentage of abnormal larvae was recorded. Hundred individuals per well were directly observed under inverted microscope (Nikon eclipse TS100/TS100-F; TS100 LED MV/ TS100 LED-F MV) to determine the number of abnormal D-shell larvae according to the criteria described in His et al. (1999) and Quiniou et al. (2005). An important prerequisite for this test is the presence, in control condition ( $24^{\circ} \mathrm{C}$ in the absence of contamination) of less than $20 \%$ of abnormal larvae. In this experimentation, four different couples were used and four replicates were performed for each condition.

\subsection{Chemical analyses}

Reference toxicants ( $\mathrm{CuSO}_{4}$ and S-metolachlor) and formalin were purchased from Sigma-Aldrich Chemical (St. Quentin Fallavier, France). Seawater was collected outside the Arcachon Bay (SW France) near the Banc d'Arguin. Immediately after sampling, seawater was filtered using membrane filter of $0.45 \mu \mathrm{m}$ and then $0.2 \mu \mathrm{m}$ (Xilab) to eliminate debris and microorganisms. FSW was stored at $4{ }^{\circ} \mathrm{C}$ in the dark and was used within 3 days. A few hours before experiment, FSW was filtered again at 0.2 $\mu \mathrm{m}$. This reference water was chemically analyzed for pollutant concentration determination.

The range of test concentrations was chosen on the basis of preliminary studies (Gamain et al., 2016). The metal and pesticide solutions were made up from analytical grade copper sulfate $\left(\mathrm{CuSO}_{4}, 5 \mathrm{H}_{2} \mathrm{O}\right)$ and S-metolachlor. Working solutions were obtained diluting the stock solutions (100 mg. $\mathrm{L}^{-1}$ for copper and 250 mg. $\mathrm{L}^{-1}$ for S-metolachlor) in FSW and were chemically analyzed. Two concentrations of exposure were selected for copper: 1 and $10 \mu \mathrm{g} \cdot \mathrm{L}^{-1}$ and three for -S-metolachlor: 10, 100 and 1000 ng. $\mathrm{L}^{-1}$. The working solutions were chemically analyzed to confirm pollutant concentrations.

\subsubsection{Copper analysis}

For chemical analysis of copper at 1 and $10 \mu \mathrm{g} \cdot \mathrm{L}^{-1}$, each seawater sample was acidified with $5 \%$ final of nitric acid (Nitric acid 65\%, Fluka). Samples were then analyzed by Inductively-Coupled Plasma Optic Emission Spectrometry (ICP-OES, Vista Pro, Agilent Technologies) and by Inductively-Coupled Plasma Mass Spectrometry (ICP-MS, Xseries2, Thermofisher Scientific). The standards solutions were prepared from a multi-elementary calibration solution (Astasol-Mix M010, Analytika, Czech Republic), in a seawater certified solution (NASS-6 from NRCC-CNRC, Ottawa, Canada). The samples were diluted in a 
3\% final nitric acid solution (made from a nitric acid 65\% FisherScientific Trace Metal Grade solution) 1:2 (v/v) for ICP-OES analysis and 1:3 (v/v) for ICP-MS analysis. Quantification limit were $10 \mu \mathrm{g} . \mathrm{L}^{-1}$ (ICPOES) and $0.3 \mu \mathrm{g} \cdot \mathrm{L}^{-1}$ (ICP-MS).

\subsubsection{Metolachlor analysis}

\section{Chemical extraction}

50-mL water samples ( $\mathrm{pH}$ adjusted to $7.0 \pm 0.1$ with $\mathrm{HCl} 0.1 \mathrm{~N}$ ) were filtered using $\mathrm{GF} / \mathrm{F}$ glass microfiber filters $(0.7 \mu \mathrm{m}$ pore size). Before analysis, pre-concentration of the analytes was performed using SolidPhase Extraction (SPE) with Oasis HLB cartridges (Waters), according to the method described by Lissalde et al. (2011). SPE was conducted using a Visiprep 12-port manifold (Supelco, France). The conditioning, extraction and rising steps were carried out under a $53.33 \mathrm{kPa}$ vaccum. The SPE cartridges were successively washed with $5 \mathrm{~mL}$ of methanol, conditioned with $5 \mathrm{~mL}$ of ultrapure water, loaded with $50 \mathrm{~mL}$ water samples, then rinsed with $5 \mathrm{~mL}$ of UPW containing $15 \%$ HPLC grade methanol. Cartridges were then dried under a nitrogen stream for $30 \mathrm{~min}$. Elutions were achieved with $3 \mathrm{~mL}$ of methanol, followed by $3 \mathrm{~mL}$ of a mix of methanol: ethyl acetate (75:25 v/v). $2.5 \mu \mathrm{L}$ of a solution of internal standard (metolachlor $\mathrm{d} 6$ ) at $1 \mathrm{ng} \mathrm{hL}^{-1}$ was then added to the 6 - $\mathrm{mL}$ extracts, followed by a solvent evaporation under a gentle stream of nitrogen and then dissolved in $250 \mu \mathrm{L}$ of UPW containing $10 \%$ HPLC grade acetonitrile prior to analysis.

\section{Instrumentation and data treatment}

Metolachlor analyses were performed by liquid chromatography ACQUITY UPLC H-Class coupled to a Xevo G2-S TOF-MS (Waters). The electrospray source was operated in positive mode at $0.7 \mathrm{kV}$ and the sample cone voltage set at $30 \mathrm{~V}$. Nitrogen was used as nebulizer (flow rate $50 \mathrm{~L} \mathrm{~h}^{-1}, 150{ }^{\circ} \mathrm{C}$ ) and desolvation gas (flow rate $1200 \mathrm{~L} \mathrm{~h}^{-1}$, temperature $600{ }^{\circ} \mathrm{C}$ ). Data was acquired in the range from 50 to $1200 \mathrm{~m} / \mathrm{z}$ and acquisition speed was set to $0.2 \mathrm{~s}$. The resolving power full width at half maximum (FWHM) was 30,000 at m/z 556.2771 (leucine encephalin used as lockmass compound). Data was acquired using MSE in order to obtain both protonated molecular ions at low collision energy ( $C E=6$ $\mathrm{eV}$ ) and/or adducts and fragment ions with a collision energy ramp (CE=10-30 eV). Separation was performed on an ACQUITY BEH C18 column $(100 \times 2.1 \mathrm{~mm}, 1.7 \mu \mathrm{m})$ from Waters (Milford, MA, USA) with a column temperature of $45^{\circ} \mathrm{C}$ and using a binary gradient of water $(A)$ and methanol (B) both containing ammonium acetate $(10 \mathrm{mM})$ at $\mathrm{pH}$ 5.0. A flow rate of $0.45 \mathrm{~mL} \mathrm{~min}{ }^{-1}$ was used and the gradient ranged as follows: $98 \%$ A (0-0.25 min), 1\% A (12.25-13 min), 98\% A (13.01-17.00). Injection volume was $20 \mu \mathrm{L}$. Data treatment was performed with MassLynx v4.1. 
Analytical method was validated in terms of calibration linearity, extraction recoveries, and limits of quantifications (LOQ) according to the French standard NF T90-210. Recovery, LOQ and LOD are showed in Table for the metolachlor into the different samples. For the quality controls, SPE was carried out routinely controlled, and the recoveries of two levels of spiked mineral water (e.g. 40 and $200 \mathrm{ng} \mathrm{L}^{-1}$ ) were evaluated for each batch. The periodic control of two calibrating standards (e.g. 2 and $25 \mu \mathrm{g} \mathrm{L}^{-1}$, every 10 samples) and analytical blanks were performed as well.

Table 2. Acquisition and validation data for the metolachlor.

\begin{tabular}{|c|c|c|c|c|c|c|c|}
\hline Compound & $\begin{array}{c}\text { Retention } \\
\text { time } \\
\text { (min) }\end{array}$ & $\begin{array}{l}\text { Quantification } \\
\text { ion }(\mathrm{m} / \mathrm{z})\end{array}$ & $\begin{array}{l}\text { Confirmation } \\
\text { ion }(\mathrm{m} / \mathrm{z})\end{array}$ & $\begin{array}{l}\text { Internal } \\
\text { standard }\end{array}$ & $\begin{array}{c}\% \\
\text { Recovery } \\
\text { ( } \pm 1 \text { SD) }\end{array}$ & $\begin{array}{l}\mathrm{LOQ}^{\mathrm{a}} \\
\text { (ng. } \mathrm{L}^{-} \\
\text {1) }\end{array}$ & $\begin{array}{l}\text { LOD }^{a} \\
\text { (ng. } \text { L }^{-} \\
{ }^{\prime} \text { ) }\end{array}$ \\
\hline Metolachlor & 9.52 & 284.142 & 176.144 & $\begin{array}{l}\text { Metolachlor } \\
\text { d6 }\end{array}$ & $110(22)$ & 0.4 & 0.1 \\
\hline $\begin{array}{l}\text { Metolachlor } \\
\text { d6 }\end{array}$ & 9.49 & 289.172 & 182.181 & N/A & $\mathrm{N} / \mathrm{A}$ & N/A & N/A \\
\hline
\end{tabular}

${ }^{\text {a }}$ Limits of quantification and detection, respectively.

\subsection{Statistical analysis}

All data is expressed as means \pm standard deviation (S.D.). Data was first processed using the transformation: $p^{\prime}=\arcsin \sqrt{p}$. P corresponds to the raw data (frequency of abnormalities) specified in $p$ values from 0 to 1 (Legendre and Legendre 1998). Homogeneity of variance (Levene's test) was verified and statistical analysis was performed by the Kruskal-Wallis tests. Differences among data from different conditions were tested using Kruskal post hoc test (equivalent to the Tuckey HSD test for non-parametric data). pattern of the different studied parameters and the relative relationship between treatment groups.

\section{Results}

\subsection{Chemical analysis}


The copper and S-metolachlor concentrations measured in the reference seawater and the different contamination solutions are shown in Table 3. Analyzes revealed the presence of copper in the reference seawater at concentrations of $3.6 \mu \mathrm{g} \cdot \mathrm{L}^{-1}$. At the nominal concentration of $1 \mu \mathrm{g} \cdot \mathrm{L}^{-1}$, the measured concentration was closed to that of control $\left(3.75 \mu \mathrm{g} \cdot \mathrm{L}^{-1}\right)$. At $10 \mu \mathrm{g} \cdot \mathrm{L}^{-1}$, the measured concentration was $18 \%$ above expected concentration. Analyzes revealed the presence of Smetolachlor in the reference seawater at concentrations lower than $5 \mathrm{ng} \cdot \mathrm{L}^{-1}$. At the nominal concentration of $10 \mathrm{ng} \cdot \mathrm{L}^{-1}$, measured concentration was $18 \mathrm{ng} \mathrm{L^{-1 }}$. At $100 \mathrm{ng} \cdot \mathrm{L}^{-1}$ and $1000 \mathrm{ng} \cdot \mathrm{L}^{-1}$ measured concentrations were closed to expected one with a range of variation of the order of $8.1 \%$ and $8.4 \%$ respectively.

Table 3: Nominal and measured copper and S-metolachlor concentrations (mean values \pm SD) at the beginning of the embryotoxicity test

\begin{tabular}{|c|c|c|c|c|c|c|}
\hline & $\begin{array}{c}\text { Nominal } \\
\text { concentrations }\end{array}$ & $\begin{array}{l}\text { Control } \\
\text { (FSW) }\end{array}$ & 1 & 10 & 100 & 1000 \\
\hline Measured & Copper $\left(\mu \mathrm{g} \mathrm{L}^{-1}\right)$ & 3.63 & 3.75 & 11.8 & - & - \\
\hline concentration & S-metolachlor (ng L-1) & 4.6 & - & 18 & 108.1 & 916 \\
\hline
\end{tabular}

\subsection{Swimming activity}

In the control, the average speed of larvae was $144.4 \pm 34.6 \mu \mathrm{m} \cdot \mathrm{s}^{-1}$ and the maximum speed was $297.3 \pm 85.2 \mu \mathrm{m} . \mathrm{s}^{-1}$ (Fig. 4) while the trajectory is mainly rectilinear $(80.8 \pm 15.6 \%$ of larvae) and to a lesser extent circular (17.5 $\pm 13.3 \%$ ). (Fig. 5).Motionless larvae are poorly observed in the control group $(1.9 \pm 3.1 \%)$. In the presence of copper, no significant difference in maximum or average larval speed was observed at the concentration of $1 \mu \mathrm{g} \cdot \mathrm{L}^{-1}$ or $10 \mu \mathrm{g} \cdot \mathrm{L}^{-1}$ compared to the control condition (Fig. 4A). After exposure to S-metolachlor, no significant difference in maximum or average larval speed was observed at the concentrations of $1 \mu \mathrm{g} \cdot \mathrm{L}^{-1}$ and $10 \mu \mathrm{g} \cdot \mathrm{L}^{-1}$ compared to the control condition (Fig. 4B). Following copper exposure at both concentrations, the percentage of circular trajectory increased significantly while the rectilinear swimming larvae significantly declined and a dose-dependent effect was observed (Fig. 5A). In the presence of S-metolachlor, the percentage of circular trajectory tends to increase with increasing S-metolachlor concentrations but it was only significant at $100 \mathrm{ng}^{\mathrm{L}} \mathrm{L}^{-1}$ (Fig. $5 B)$. In the meanwhile, rectilinear trajectories were reduced at all concentrations tested but it was only significant at 10 and $1000 \mathrm{ng} \cdot \mathrm{L}^{-1}$. 
Table 3: Abnormal larvae and malformation frequency in oyster larvae exposed to copper or S-

\section{Metolachlore}

\begin{tabular}{lllll}
\hline Conditions & $\begin{array}{l}\text { Abnormal } \\
\text { larvae }\end{array}$ & $\begin{array}{l}\text { Development } \\
\text { arrest }\end{array}$ & $\begin{array}{l}\text { Mantle } \\
\text { anomalies }\end{array}$ & Shell anomalies \\
\hline Control & $17.0 \pm 2.42$ & $4.05 \pm 1.85$ & $7.4 \pm$ & $5.55 \pm$ \\
Cu 1 & $36.98 \pm 3.30$ & $10.94 \pm 2.49$ & $14.5 \pm$ & $11.79 \pm$ \\
Cu 10 & $60.31 \pm 6.6$ & $19.67 \pm 1.61$ & $25.89 \pm$ & $14.75 \pm$ \\
Met 10 & $32.48 \pm 11.51$ & $14.38 \pm 3.21$ & $12.58 \pm$ & $5.52 \pm$ \\
Met 100 & $47.75 \pm 12.58$ & $18.70 \pm 5.52$ & $12.15 \pm$ & $16.9 \pm$ \\
Met 1000 & $59.15 \pm 5.24$ & $28.60 \pm 9.89$ & $16.20 \pm$ & $14.35 \pm$ \\
\hline
\end{tabular}

281

Abnormal larvae average frequency was $17.0 \pm 2.4 \%$ in control condition (Fig. 6 and Table 3). The percentage of developmental arrest increase significantly at $10 \mu \mathrm{g} \cdot \mathrm{L}^{-1}$ of copper while a dosedependent increase of malformed larvae was observed at all copper concentration tested (Fig. 6A and Table 3). After exposure to S-metolachlor the percentage of developmental arrest was significantly increased from $100 \mathrm{ng}^{-L^{-1}}$ whereas the percentage of abnormalities increased significantly only at 1000 ng. $\mathrm{L}^{-1}$ (Fig. $6 \mathrm{~B}$ and Table 3).

\subsection{Relationship between malformations and swimming behavior}

PCA featured $60.88 \%$ of the selected variables considering the two first axes. The first axis accounted for $38.23 \%$ while le second axis accounted for $22.65 \%$ of the variability.

For the plot of variables (Fig 7A), the PC1 was positively loaded by both circular trajectories and shell abnormalities, and negatively loaded by rectilinear trajectories. PC2 was negatively loaded by maximum and average speeds. Rectilinear trajectories appeared positively correlated to normal larvae $(r=0.47, p=0.012)$ while larvae with shell anomalies were positively correlated to circular trajectories $(r=0.60, p=0.001)$. In addition, motionless larvae were obviously anti-correlated to maximum and average speeds.

298 For the plot of treatment groups (Fig. 7B), the PC1 and PC2 allowed a good separation of the control 299 group versus copper $1 \mu \mathrm{g} / \mathrm{L}$ and copper $10 \mu \mathrm{g} / \mathrm{L}$ groups. The separation of the control group and 
metolachlor $100 \mathrm{ng} / \mathrm{L}$ and metolachlor $1000 \mathrm{ng} / \mathrm{L}$ groups was well defined. In contrast, the metolachlor $10 \mathrm{ng} / \mathrm{L}$ group was partly overlapping with the control, metolachlor 100 and $1000 \mathrm{ng} / \mathrm{L}$ groups.

Le groupe contrôle est bien associée à des larves normales et à des trajectoires rectilignes (Figure 7 A\&B). Les malformations du manteau sont corrélées principalement à l'exposition au cuivre à $10 \mu \mathrm{g} / \mathrm{L}$ et au S-metalchlor à $1000 \mathrm{ng} / \mathrm{L}$.

\section{Discussion}

\subsection{Normal swimming behavior of oyster D-larvae}

The herein described video tracking system represents an operational tool to evaluate different swimming parameters of D-larvae of the Pacific oyster Crassostrea gigas. A lot of others automated systems have been described to analyze swimming activity, motility or frequency of pulsation in numerous invertebrates (for review see Faimali et al., 2017) but to our knowledge, this study is the only one analyzing both swimming speed and trajectory.

Our semi-automated video tracking system was able to identified three major types of traces of larval path: rectilinear, circular and motionless. It is to be noted that the identified three traces of larval path do only consider two dimensions and that larvae oysters moving in their environment can move in three dimensions. A study on three dimensions would not affect rectilinear paths but circular paths might split between real circles and 3D spirals.

In our experiment, under optimal development conditions $\left(24^{\circ} \mathrm{C}\right.$, salinity of 33 usi), oyster larvae mainly adopted rectilinear trajectories $(81 \% \pm 15)$. Thus, the most common behavior of the larvae would correspond to rectilinear swimming. These results confirm the early work of His et al. in 1989 on the mussel Mytilus galloprovincialis, which suggested that a circular or spiral swimming denoted an erratic behavior of the larvae.

In the same laboratory conditions $\left(24^{\circ} \mathrm{C}\right.$, salinity of $\left.33 \mathrm{usi}\right)$, the average speed and the mean maximum velocity of oyster D-larvae were 144 and $297 \mu \mathrm{m} . \mathrm{s}^{-1}$, respectively. Suquet et al., (2012) reported an average swimming speed of $105 \mu \mathrm{m} . \mathrm{s}^{-1}$ for $C$. gigas D-larvae in the absence of contamination. This value is slight lower than the one calculated in our study. This difference can be explained, at least in part, by the temperature difference between the two experiments, e.g. $19{ }^{\circ} \mathrm{C}$ for Suquet's study and $24^{\circ} \mathrm{C}$ for this study. $24^{\circ} \mathrm{C}$ correspond to the ideal temperature of development for $\mathrm{C}$. gigas (AFNOR, 2009, Gamain et al., 2016). Incubation of C. gigas embryos at temperature less than or equal to $20^{\circ} \mathrm{C}$ give rise to significant increase of developmental abnormalities (Gamain et al., 2016). Those abnormalities have likely consequences on the behavior and the speed of swimming of larvae. Indeed, 
Horiguchi et al., (1998) reported unusual swimming behavior, low swimming activity and irregular movement of cilia due to atrophy of velum in larvae of different mollusk species exposed to organotin compounds.

\subsection{Effect of model pollutants on swimming behavior of oyster D-larvae}

In our experimental setup $\left(24^{\circ} \mathrm{C}\right.$, salinity of 33 usi), there are no significant differences of the average and maximum swimming speeds up to $10 \mu \mathrm{g} / \mathrm{L}$ of copper and $1 \mu \mathrm{g} / \mathrm{L}$ of S-metolachlor. In contrast, the percentage of rectilinear larval paths decreased with the concentration of copper and S-metolachlor (except for the $1000 \mathrm{ng} / \mathrm{L}$ ) while the percentage of circular larval paths increases with the concentration of copper and S-metolachlor (except for the $1000 \mathrm{ng} / \mathrm{L}$ ). Absence of effect on swimming speed means that the two compounds did not targeted the metabolism and/or the neuro-muscular system of oyster D-larvae. Besides, a significant change of the larval trajectory was observed at the lowest tested concentrations of copper $(1 \mu \mathrm{g} / \mathrm{L})$ and S-metolachlor $(10 \mathrm{ng} / \mathrm{L})$ with a striking shift of rectilinear paths to circular ones. This trajectory shift was likely associated to the appearance of morphological anomalies in developing oyster embryos since a significant positive correlation was noted between circular trajectory and shell abnormality of D-larvae.

No data is available about effect of S-metolachlor on swimming activity of aquatic organisms. Besides, a few works have documented effects of copper on fish and invertebrates. LaBretech et al. (2002) observed a decrease of motility in larvae of Mercenaria mercenaria exposed to concentration of $\mathrm{Cu}$ above 10 Mg/L. Kwok and Ang (2013) also reported a significant inhibition of swimming activity of larvae of the coral Platigyra acuta at concentration above $40 \mu \mathrm{g} / \mathrm{L}$. After $48 \mathrm{~h}$ of depuration the larval motility was not recovered indicating a possible persistent effect of copper. In zebrafish larvae exposed to $\mathrm{Cu}$ concentrations from 9-20 $\mu \mathrm{g} / \mathrm{L}$, the mean and the maximal velocity were significantly increased, but not effect was observed at higher concentrations (Da Silva Acosta et al., 2016).

Toxicity of copper and S-metolachlor on early life stage of aquatic species is well document. It has been shown that both compounds induced significant developmental anomalies and DNA damage in bivalves at environmentally realistic concentrations (Mai et al., 2012; 2013; Gamain et al., 2017). Behavior is an integrated and whole-organism response (Faimali et al., 2017). Punctual and/or limited modifications of this behavior is assume to be an immediate and adaptive response to stress. At the contrary, permanent and deep perturbations of behavior are the results of irreversible changes at the sub-individual level that can have dramatically impact on fitness and survival of individuals. The significant positive correlation between circular trajectory and anomalies of the shell in oyster larvae exposed to copper or S-metholachlor demonstrate the deep impact of these molecules on the embryo- 
larval development of this specie. This study demonstrates, once again, the very high sensitivity of the early development stages of oyster to chemical contamination.

\subsection{Application of swimming activity monitoring of oyster larvae}

Since a decade, researchers are using swimming activity in model vertebrates (Le Bihanic et al., 2015; XXX) and invertebrates (Chevalier et al., 2015; XXXX) as new endpoints to evaluate toxicity of chemicals. This kind of endpoint is increasingly used for environmental risk or water quality assessment in non-model organism such as crustacean and sea urchin (Garaventa et al., 2010; Morgana et al., 2016). Although mussels and oysters are widely used as sentinel species for pollution monitoring, to date very few works focused on swimming behavior of bivalves exposed to pollutants (Horiguchi et al., 1998).

In the present study, effect of pollutants was clearly detected on swimming behavior of oyster larvae at concentrations as low as $1 \mu \mathrm{g} / \mathrm{L}$ of copper and $10 \mathrm{ng} / \mathrm{L}$ of S-metolachlor. These levels of contamination are environmentally relevant and are currently detected in seawater of numerous European coastal areas (XXXX) and notably in the Arcachon Bay (Gamain et al., 2017b). The swimming activity of oyster larvae could be used as an early warming indicator of the quality of water and/or of the toxicity of pollutants.

Abnormal swimming behavior of D-larvae can directly affect their survival or fitness. In addition, abnormal trajectories can impair dispersion of larvae and colonization of new habitats. Both phenomenon could impair recruitment and at terms impact survival of wild population and viability of production of oysters. In this respect, swimming behavior could be used as a suitable tool to analyze the health status of larvae from wild or farmed oyster populations.

In the future, we can expect the use of video-tracking of oyster larvae as a convenient tool to guide the shellfish farmers towards the choice of the best batch of larvae and environmental agencies for the assessment of coastal water quality.

\section{Conclusion}

This study describes a semi-automated image analysis tool to analyze D-larvae swimming behavior of bivalves. Oyster larvae exposed to environmental concentrations of copper or S-metolachlor showed aberrant swimming trajectories but average and maximum speeds were not impacted. Rectilinear trajectories appeared positively correlated to normal larvae while larvae with shell anomalies were positively correlated to circular trajectories. This study showed that video-tracking of oyster swimming 
behavior is a sensitive and easy to perform tool for ecotoxicological testing. The use of this tool at large scale could need some improvements in particular for temperature control and automating of trajectory reading.

\section{Acknowledgments}

The authors thank the Aquitaine Region (OSQUAR Project), CPER A2E, Intermunicipal Union of Arcachon Bay (SIBA) and Water Agency Adour Garonne (AEAG) for their financial support. This work was part of the LABEX COTE cluster of excellence "Continental To coastal Ecosystems: evolution, adaptability and governance".

\section{References}

Chevalier J., Harscoët E., Keller M., Pandard P., Cachot J., Grote M., 2015. Exploration of Daphnia behavioral effect profiles induced by a broad range of toxicants with different modes of action. Environ. Toxicol. Chem., 34: 1760-1769.

Da Silva Acosta, D., Danielle, N.M., Altenhofen, S., Luzardo, M.D., Costa, P.G., Bianchini, A., Bonan, C.D., Da Silva, R.S., Dafre, A.L., 2016. Copper at low levels impairs memory of adult zebrafish (Danio rerio) and affects swimming performance of larvae. Comparative Biochemistry and Physiology Part - C: Toxicology and Pharmacology 185-186: 122-130

Faimali M., Gambardella C., Costa E., Piazza V., Morgana S., Estevez-Calvar N., Garaventa F., 2017. Old model organisms and new behavioral end-points: Swimming alteration as an ecotoxicological response. Marine Environmental Research 128: 36-45.

Horiguchi, T., Imai, T., Cho, H.S., Shiraishi H, Shibata Y, Morita, M., Shimizu, M., 1998. Acute toxicity of organotin compounds to the larvae of the rock shell, Thais clavigera, the disk abalone, Haliotis discus and the giant abalone, Haliotis madaka. Marine Environmental Research 46(1-5):469-473 Kapur JN, Sahoo PK, Wong AKC, "A new method for gray-level picture thresholding using the entropy of the Histogram" Computer Vision graphics and image processing, vol. 29, pp 273-285, 1985 LaBreche, T.M.C., Dietrich, A.M., Gallagher, D.L., Shepherd, N., 2002. Copper toxicity to larval Mercenaria mercenaria (hard clam). Environmental Toxicology and Chemistry 21(4), pp. 760-766 Le Bihanic F., Sommard V., de Lansalut P., Anaïk P., Grasset J., Berrada S., Budzinski H., Cousin X., Morin B., Cachot J., 2015. Environmental concentrations of benz[a]anthracene induce developmental defects and DNA damage and impair photomotor response in Japanese medaka larvae. Ecotoxicology and Environmental Safety, 113: 321-328. 
432 Combined effects of temperature and copper and S-metolachlor on embryo-larval development of the 433 Pacific oyster, Crassostrea gigas. Marine Pollution Bulletin, 115: 201-210.

434 Gamain P., Cachot J., Gonzalez P., Budzinski H., Gourves P.-Y., Morin B., 2017d. Do temporal and spatial parameters or lifestyle of the Pacific oyster Crasssostrea gigas affect pollutant bioaccumulation, offspring development and tolerance to pollutants? Frontiers in Marine Science, 4, 58 DOI 10.3389/fmars.2017.00058.

Garaventa, F., Gambardella, C., Di Fino, A., Pittore, M., Faimali, M., 2010. Swimming speed alteration of Artemia sp. and Brachionus plicatilis as a sub-lethal behavioural end-point for ecotoxicological survey. Ecotoxicology 19: 512-519

Mai H.., Cachot J., Brune J., Geffard O., Belles A., Budzinski H., Morin B., 2012. Embryotoxic and genotoxic effects of heavy metals and pesticides on early life stages of Pacific oyster (Crassostrea gigas). Marine Pollution Bulletin, 64 : 2663-2670.

444

445

446

447

448

449

450

451

452

453

454

455

456

457

458

459

460

461

462

463

464

465

466

Mai H., Morin B., Pardon P., Gonzalez P., Budzinski H., Cachot J., 2013. Environmental concentrations of irgarol, diuron and S-metolachlor induce deleterious effects on gametes and embryos of the Pacific oyster, Crassostrea gigas. Marine Environmental Research, 89: 1-8.

Morgana, S., Gambardella, C., Falugi, C., Pronzato, R., Garaventa, F., Faimali, M., 2016. Swimming speed alteration in the early developmental stages of Paracentrotus lividus sea urchin as ecotoxicological endpoint. Marine Environmental Research 115: 11-19

Nussbaum-Krammer Cl, Neto MF, Brielmann RM, Pedersen JS, Morimoto RI, 2015. Investigating the spreading and toxicity of prion-like proteins using the metazoan model organism C. elegans. Journal of Visualized Experiments (95),e52321

Suquet M., Le Mercier A., Rimon F., Mingant C., Haffray P., Labbe C., 2012. Setting tools for the early assessment of the quality of thawed Pacific oyster (Crassostrea gigas) D-larvae. Theriogenology 78: $462-467$

Troost K., Veldhuizen R., Stamhuis E. J., Wolff W. J., 2008. Can bivalve veligers escape feeding currents of adult bivalves? Journal of Experimental Marine Biology and Ecology 358: 185-196

Kwok, C.K., Ang, P.O., 2016. Inhibition of larval swimming activity of the coral (Platygyra acuta) by interactive thermal and chemical stresses. Marine Pollution Bulletin 74(1), pp. 264-273

\section{Figures}

Figure 1: sampling site for mature oysters in the Arcachon Bay (SX France): 1) Les Jacquets, 2) Comprian and 3) Banc d'Arguin.

Figure 2: Image Analysis: A) Original image, B) Grayscale image, C) 'Binarized' image, D) Traces of larval path, E) Quantified parameters. 
467 Figure 3: Gathering drawing with different traces of larval paths: 1) Rectilinear, 2) Circular, 3)

468 Motionless, 4) larval enters and exits field of view, 5) collision between two larvae.

469 Figure 4: Average and maximum speed $\left(\mu \mathrm{m} \cdot \mathrm{s}^{-1}\right)$ of D-larvae exposed to different concentrations of $(A)$ copper ( $\left.\mu \mathrm{g} . \mathrm{L}^{-1}\right)$ or (B) S-metolachlor $\left(\mathrm{ng} . \mathrm{L}^{-1}\right)$. Data points represent mean \pm SD with 3-5 replicates per concentration and 12-74 larvae for each replicate.

472 Figure 5: Trajectories of D-larvae exposed to different concentrations of (A) copper ( $\left.\mu \mathrm{g} . \mathrm{L}^{-1}\right)$ or (B) S473 metolachlor $\left(n g . \mathrm{L}^{-1}\right)$. Data points represent mean \pm SD with 3-5 replicates per concentration and 12-74 474 larvae for each replicate. Different letters indicated significant differences between exposure 475 conditions $(p<0.05)$.

476 Figure 6: Percentages of developmental arrest (DA) and abnormal D-larvae exposed to different 477 concentrations of $(A)$ cooper $\left(\mu \mathrm{g} \cdot \mathrm{L}^{-1}\right)$ or $(B)$ S-metolachlor $\left(n g . \mathrm{L}^{-1}\right)$. Data points represent mean \pm SD. $478 \mathrm{~N}=4$ replicates per condition, and 100 larvae for each replicate. Different letters indicated significant 479 differences between exposure conditions $(p<0.05)$. Figure 7: Principal component analysis of the different types of abnormalities and trajectories of Dlarvae. Analysis represents normalized coefficients on the first two axes (axis 1: $38.23 \%$; axis 2: 22.65\%) for three D-larvae abnormalities (normal, shell abnormalities, mantle abnormalities), three trajectories ( $R$ : Rectilinear ; S: Motionless, C: Circular) two speed (Vit Moy: average speed, Vit Max: maximum speed). The variables factor map is shown in (A) and the individual factor map in (B). Pearson correlation analysis between shell abnormalities and circular trajectories (C), and rectilinear trajectories and normal D-larvae (D). 


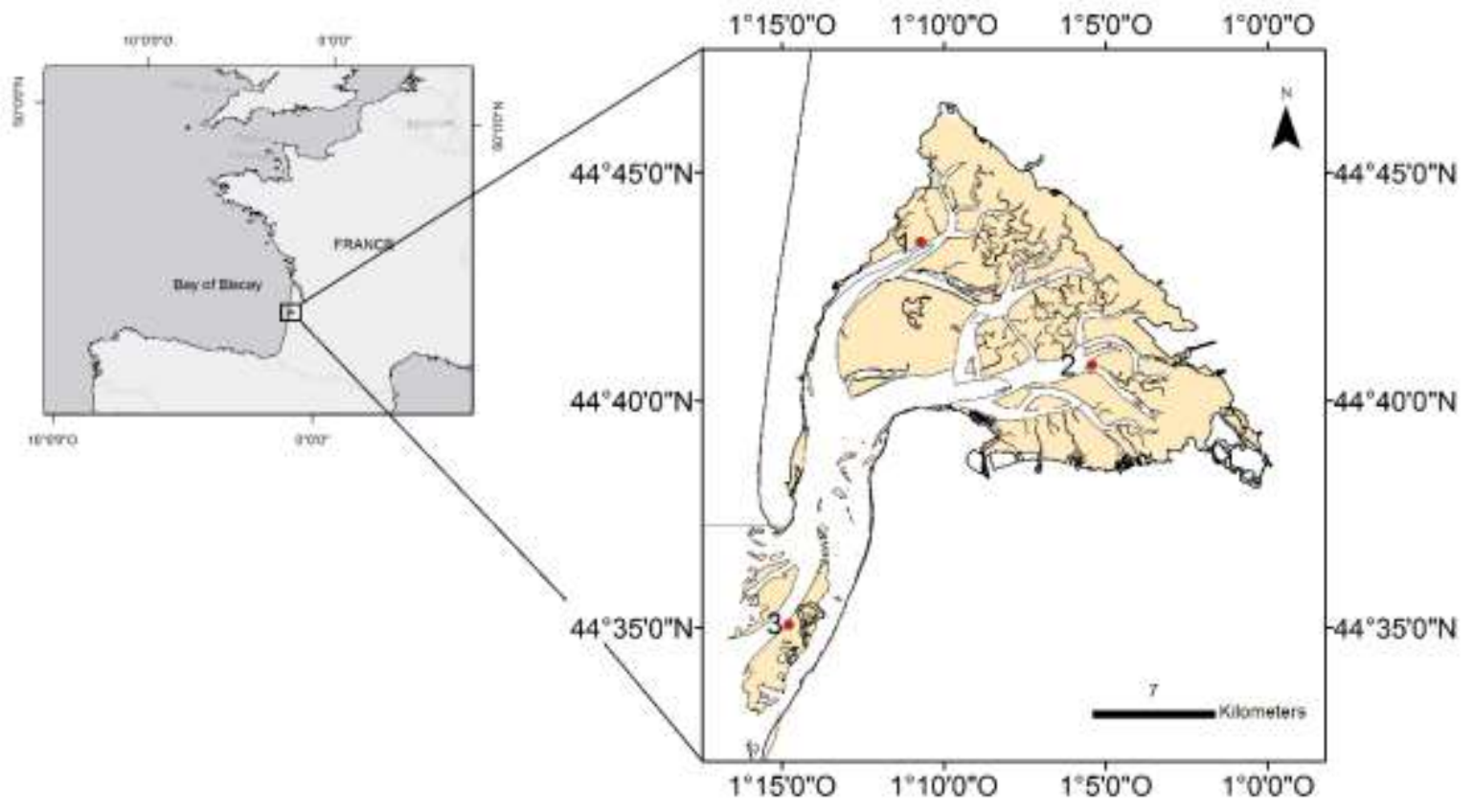

490

491 Figure 1

492 


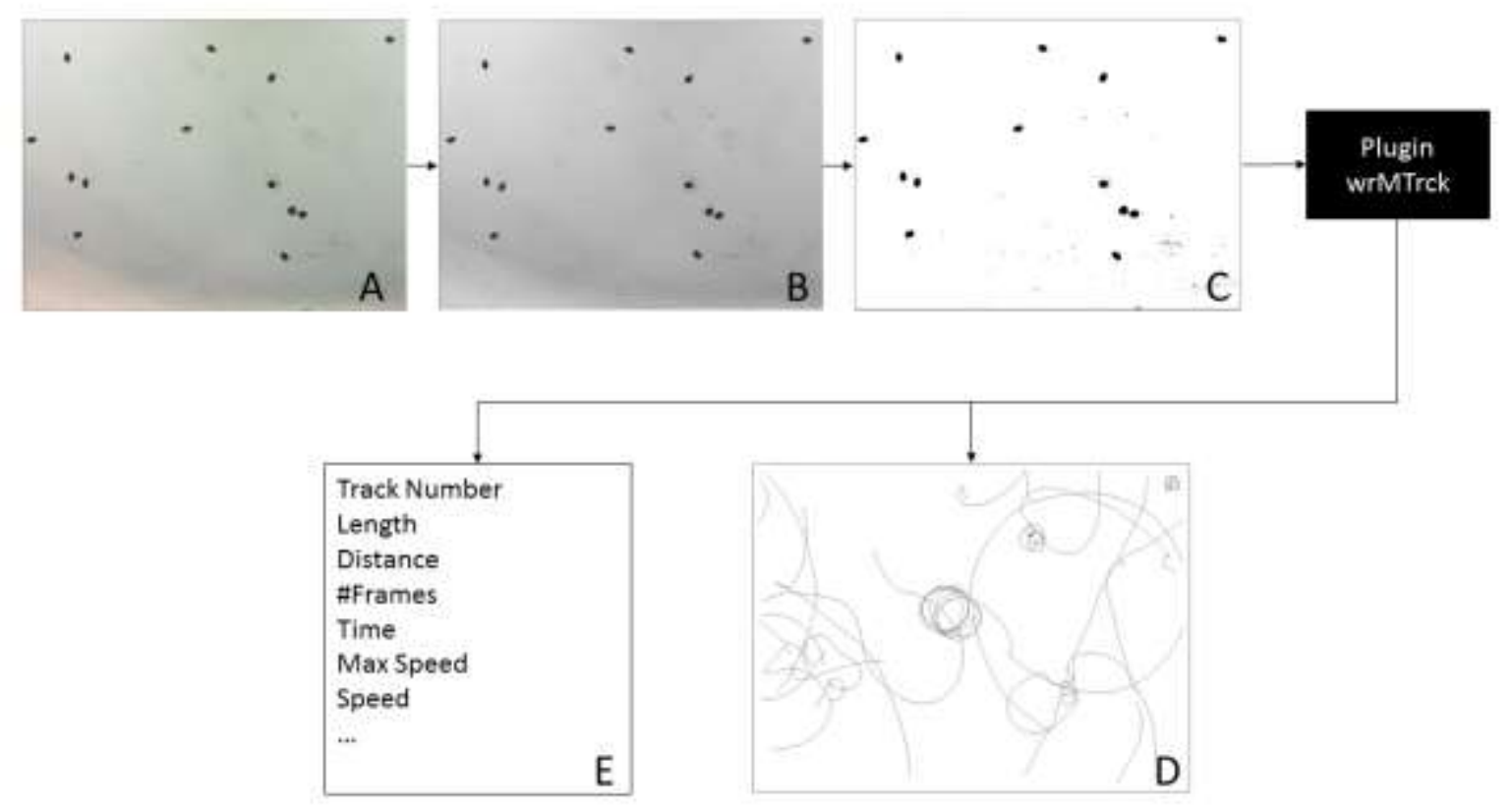

493

494 Figure 2

495

496 


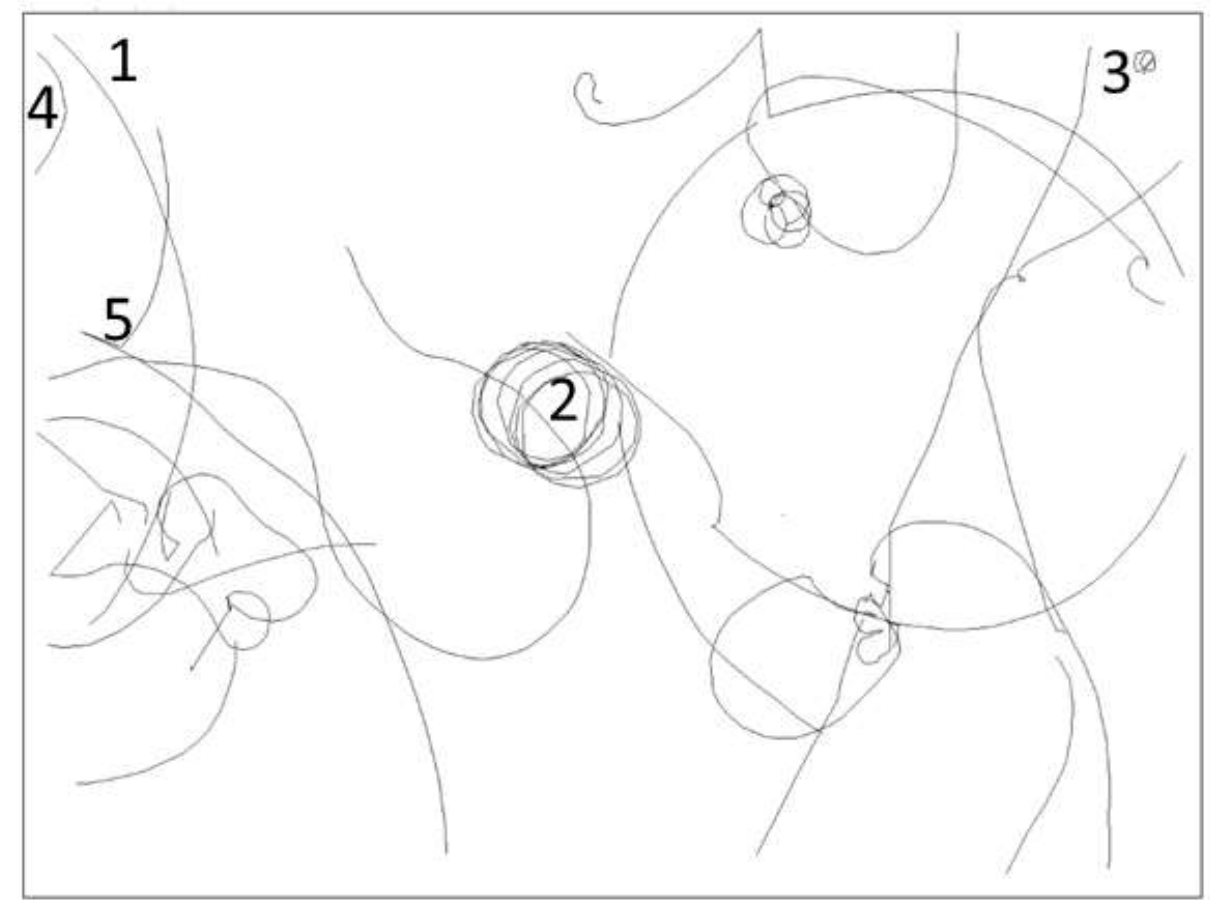

497

498

Figure 3

499 

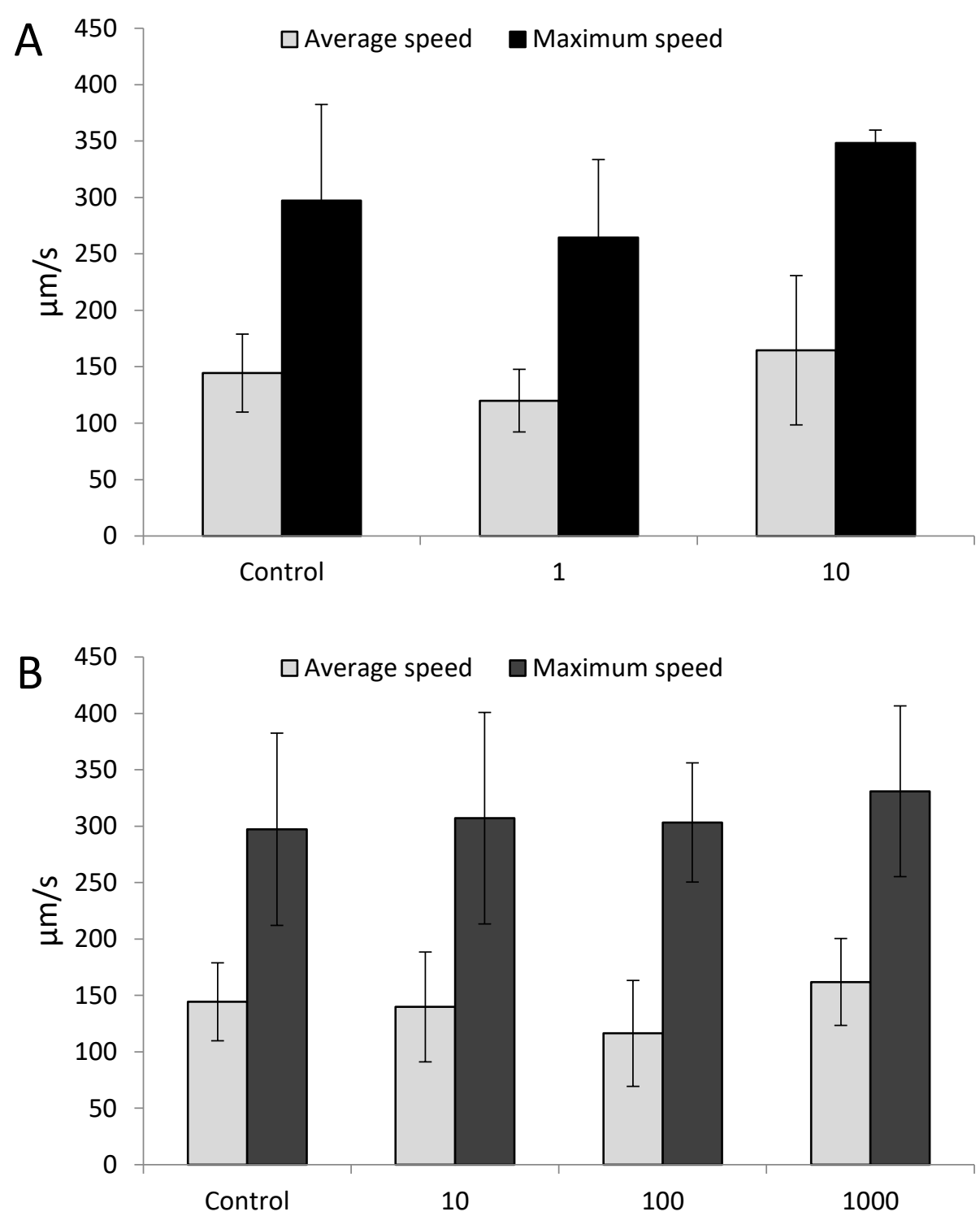

501

502

503

Figure 4

504

505

506 

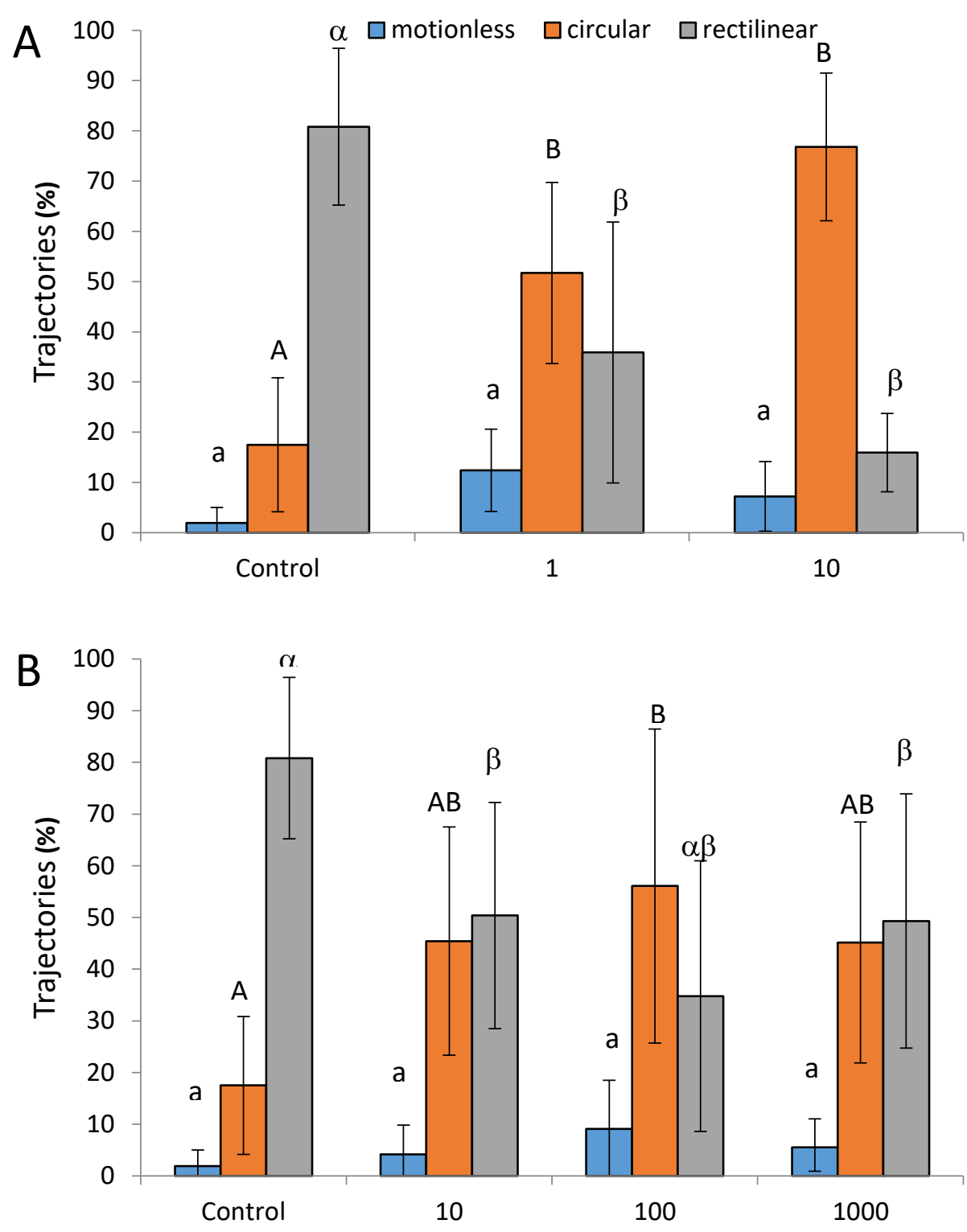

509

Figure 5

510 


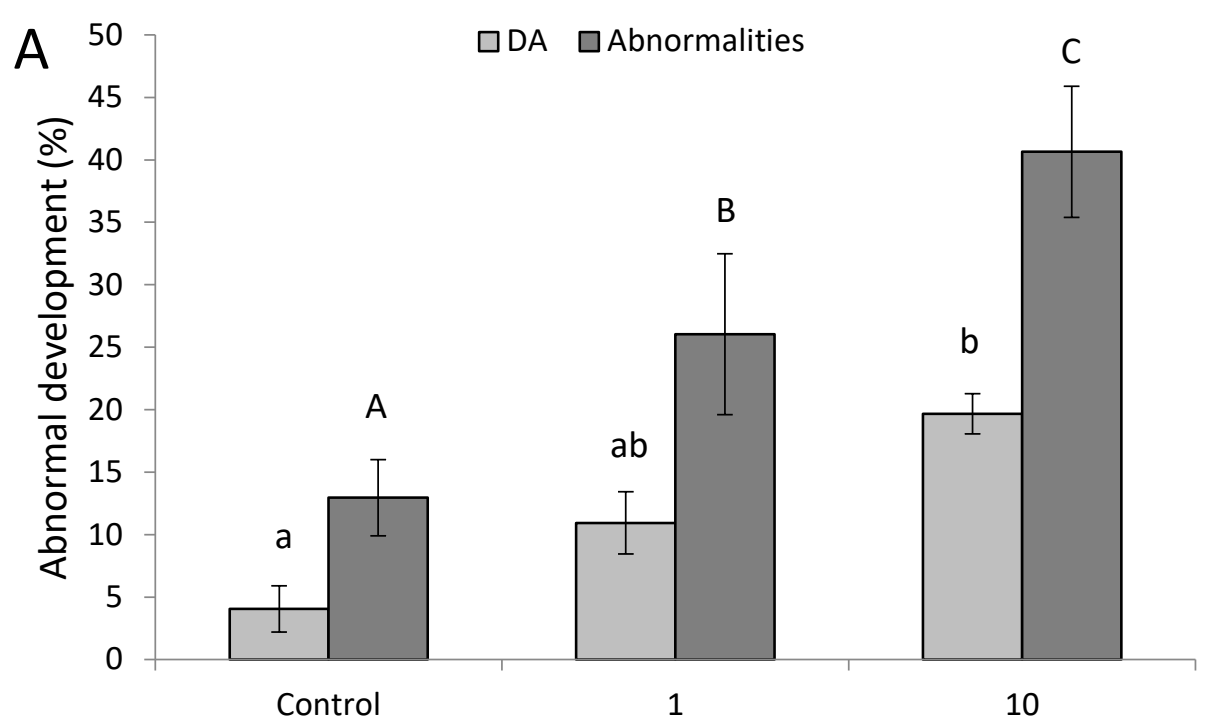

513

514

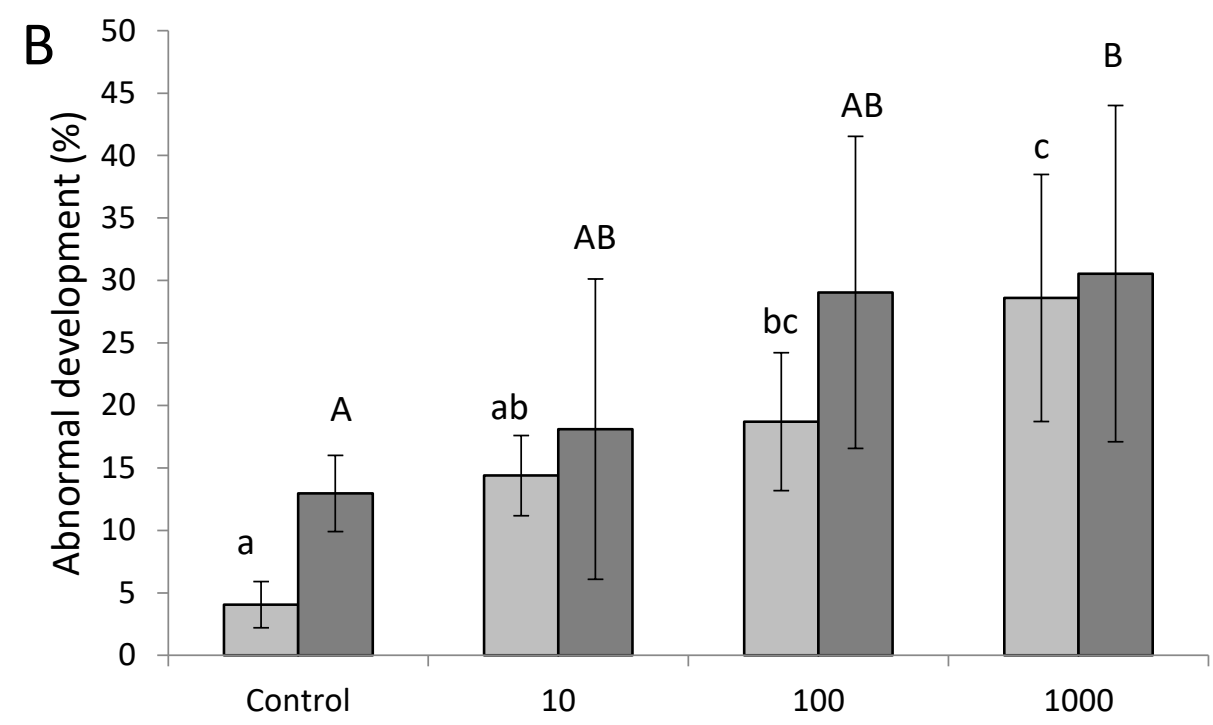

$515 \quad$ Figure 6

516 

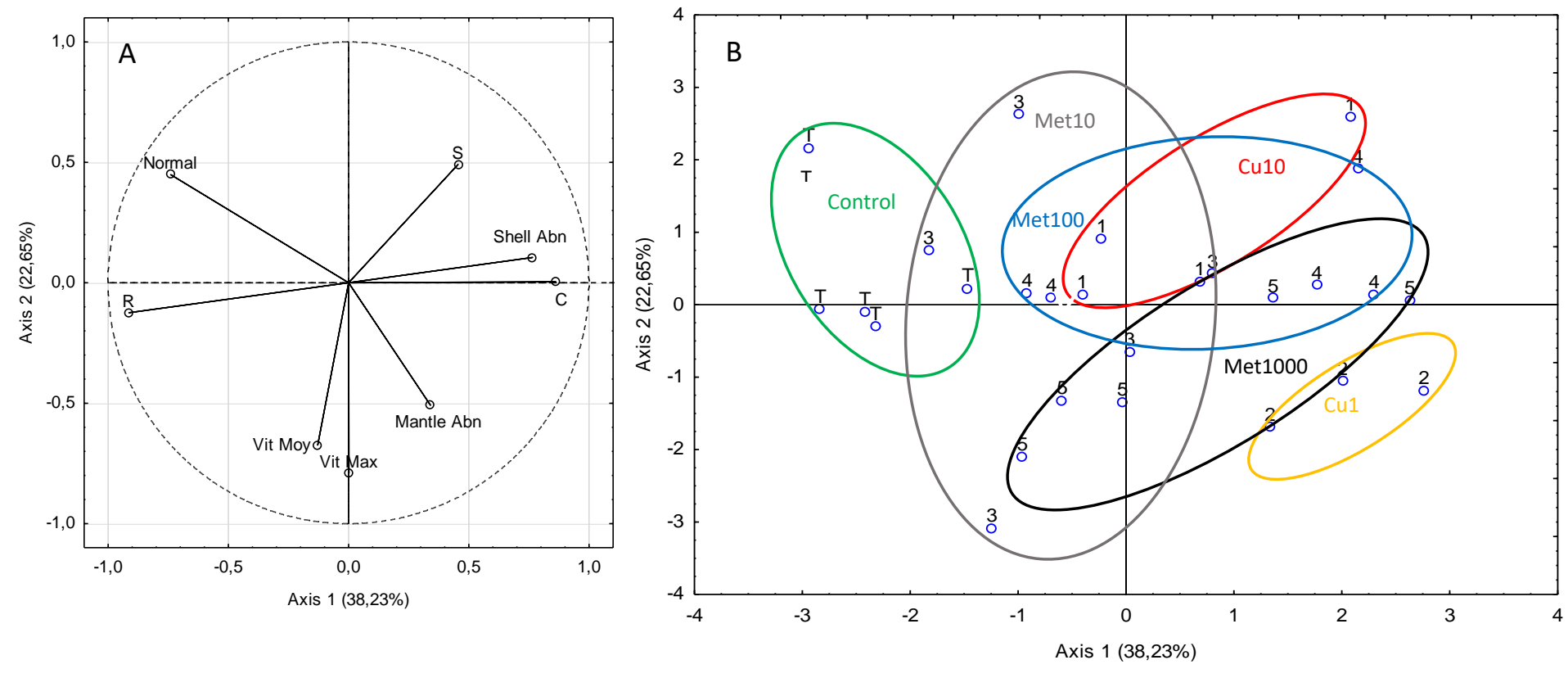
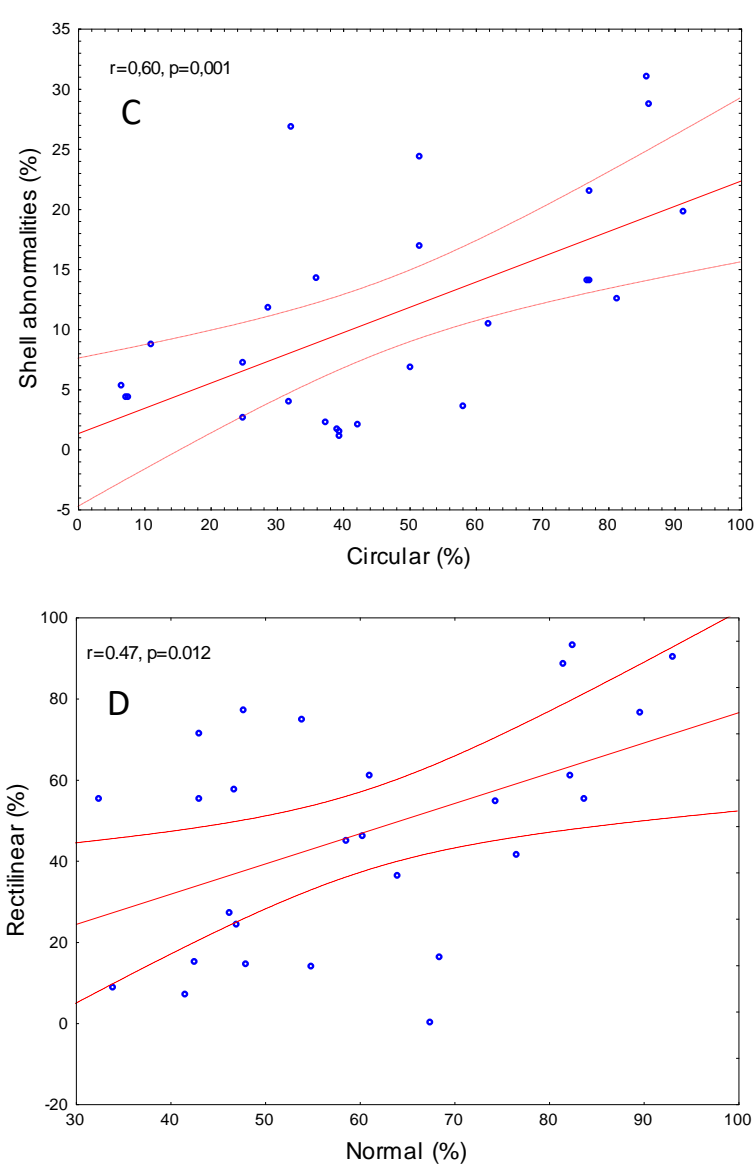

Figure 7 
